\title{
Praticando a equidade: estratégias de efetivação de direitos no trabalho doméstico
}

LOUISA ACCIARI I e TATIANE PINTO ${ }^{I I}$

\section{Introdução}

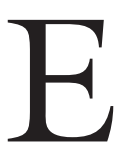
M JUNHO de 2015, o Congresso brasileiro aprovou a Lei Complementar n.150 que estende a maioria dos direitos trabalhistas à categoria das trabalhadoras domésticas, um grupo historicamente estigmatizado como "nãotrabalhadoras" e excluído da CLT. Essa alteração no sistema jurídico e político brasileiro foi tão significativa que a lei foi descrita como uma "segunda abolição da escravidão" por muitos políticos e pelo próprio governo do Partido dos Trabalhadores (PT).

O trabalho doméstico no Brasil é moldado pelas desigualdades de gênero, raça e classe, herdadas da história colonial, que posicionaram as mulheres negras como as principais provedoras do trabalho reprodutivo (Bernardino-Costa, 2015; Gonzalez, 1984). No período atual, há um contingente de, aproximadamente, 6,4 milhões de trabalhadoras domésticas, sendo 93\% mulheres e $61 \%$ mulheres negras, e a ocupação ainda representa o maior setor de emprego para as mulheres negras. As trabalhadoras domésticas continuam recebendo uma remuneração abaixo do salário mínimo e $70 \%$ delas não possui carteira de trabalho assinada (Dieese, 2013, 2017).

Em reação a essas desigualdades arraigadas na história colonial e suas decorrentes discriminações legais, as trabalhadoras domésticas vêm se mobilizando, desde 1936, para exigir direitos iguais e serem reconhecidas como cidadãs e trabalhadoras. Com a aprovação da Lei n. 150/2015, surge a impressão de que, finalmente, após 80 anos de mobilizações e séculos de desvalorização de seu trabalho, a categoria estava finalmente tendo suas demandas ouvidas. No entanto, a legislação de 2015 não foi a revolução prometida: não equiparou totalmente os direitos da categoria, além de conter artigos que reproduzem e legitimam novas formas de exploração (como a discriminação da diarista) e foi adotada em meio a um contexto de crise política que lança importantes dúvidas sobre sua implementação. Apenas um ano após a aprovação da Lei n.150/2015, o governo do PT foi impugnado e substituído por uma coalizão conservadora com uma 
agenda de desregulamentação do mercado de trabalho e desmantelamento dos direitos humanos. Em continuidade a esse movimento conservador, o deputado Jair Bolsonaro, que orgulhosamente afirma ter sido o único a votar contra a lei das trabalhadoras domésticas, venceu a eleição presidencial em outubro de 2018. Diante desse quadro, cabe perguntarmos como as trabalhadoras domésticas podem defender e efetivar seus direitos, tão dificilmente conquistados?

Neste artigo, interessa-nos compreender quais são as estratégias desenvolvidas pelas trabalhadoras domésticas (sindicalizadas ou não) para revalorizar uma atividade tão socialmente desvalorizada, e por quais meios elas podem tornar seus direitos efetivos. Refletiremos sobre como tais direitos são requeridos em seu cotidiano de trabalho na casa dos patrões, e quando são acionadas estratégias de resistência em oposição à opressão sofrida nesses espaços e nas relações em que se idealiza o mando-obediência que ameaça a efetivação daquilo que essas trabalhadoras entendem por direitos. Por fim, procuramos identificar como essas mulheres conseguem elaborar a percepção de dignidade, ou mantê-la, em um setor tão profundamente marcado pela desigualdade e exploração.

Nossa análise se fundamenta em dois diferentes estudos, cujas indagações se complementam: um deles versa sobre as trajetórias de vida de trabalhadoras na Baixada Fluminense (Pinto, 2019), e o outro sobre a formação e atuação dos sindicatos da categoria (Acciari, 2018). No campo dessas duas pesquisas foram realizadas, aproximadamente, 137 entrevistas, com mulheres, em sua maioria negras, com atuação no serviço doméstico remunerado, trabalhadoras sindicalizadas e outras não sindicalizadas.

A pesquisa específica sobre as trabalhadoras domésticas da Baixada Fluminense teve como foco identificar os modos como essas mulheres elaboram os significados de sua ocupação, explorando dimensões de seu entendimento sobre família, experiência feminina, aprendizado doméstico, trabalho e direitos. Foram enfatizadas as formas diárias e habituais de resistência dessas trabalhadoras, tanto em seus espaços de trabalho, como na relação com as famílias empregadoras e também em espaços políticos como os sindicatos da categoria.

No segundo estudo, deu-se ênfase aos espaços dos sindicatos de trabalhadoras domésticas, onde procurou-se esclarecer como uma categoria tão estigmatizada alcançou uma forma impactante de organização, que levou à obtenção de uma reforma constitucional em 2013 e à aprovação da lei 150 no ano de 2015 . O lócus deste trabalho se deu entre 2015 e 2018, com etnografia de seis sindicatos (São Paulo, Campinas, Franca, Volta Redonda, Nova Iguaçu e Rio de Janeiro) afiliados a Federação Nacional das Trabalhadoras Domésticas (Fenatrad).

Seguiremos a discussão por meio de três eixos: um que trata das negociações de ordem individuais nas relações de trabalho, e uma compreensão prática dos direitos por parte das trabalhadoras domésticas; outro em que abordaremos a educação legal popular organizada pelos sindicatos para conscientizar a categoria e dar-lhes instrumentos para se defender coletivamente; e por fim, 
discutiremos sobre o efeito emancipador dos direitos nas ações dos sindicatos, por meio dos discursos de cidadania, democracia e através do fortalecimento de redes com outros movimentos e instituições. Demonstraremos que, apesar de serem limitados e paradoxais, os direitos são instrumentos fundamentais nas mobilizações das trabalhadoras domésticas, lhes proporcionando vocabulários de luta, legitimidade política e ganhos materiais.

\section{Feminismos, direitos e mobilizações sociais}

A literatura feminista parece bastante dividida sobre a questão do uso da lei e da política de direitos; enquanto algumas autoras enxergam os direitos humanos como uma ferramenta para alcançar a igualdade de gênero (Mackinnon, 1994; Pitanguy, 2002), outras avaliaram criticamente as relações de poder decorrentes da produção e implementação desses direitos (Abu-Lughod, 2002; Grewal, 2005; Mohanty, 1988). Se os direitos humanos se destinam a reparar lesões ou situações de desigualdades, muitos autores mostraram que por si só os direitos não podem transformar o contexto que produziu desigualdades sociais (Bradshaw, 2006; Gideon, 2006; Kabeer, 2004). Além disso, uma política de direitos implica uma forte dependência do Estado para garantir e implementar os direitos humanos, quando o Estado é frequentemente o local onde a violência inicial foi produzida. Cornwall e Molyneux (2006) argumentam que qualquer relação com o Estado leva ao risco de comprometer os objetivos da justiça social.

Outro desafio é o tipo de sujeitos produzidos pelos discursos sobre direitos. Spivak (2003) argumentou que, para que os direitos sejam efetivos, eles pressupõem a existência de um sujeito liberal, respondendo a uma concepção universal abstrata do humano. Nessa perspectiva, os direitos humanos tornam-se uma forma de regulação de corpos e subjetividades, e não uma prática emancipatória. Nesse sentido, alguns autores afirmam que os direitos humanos aprisionam as mulheres na posição de vítima, mãe ou sujeito feminino heterossexual, reproduzindo assim os desequilíbrios de poder que mantêm a opressão das mulheres (Cornwall et al., 2008) e condenando-as a "sofrer direitos como paradoxos" (Brown, 2000).

No entanto, apesar dessas perspectivas críticas, os direitos também são inevitáveis e necessários. Os direitos humanos são um terreno de lutas e possibilidades, representando uma das estratégias políticas mais amplamente utilizadas por mulheres e movimentos subalternos em nível global (Collins et al., 2010). Como tal, essas práticas não podem ser desconsideradas. De fato, os direitos estão sendo cada vez mais mobilizados a ponto de alguns falarem em judicialização da política (Domingo, 2009; Sieder et al., 2005). Segundo Couso et al. (2013), a judicialização é um processo que está acontecendo além dos tribunais: nas esferas informais, subnacionais e transnacionais, onde lei e direitos estão sendo mobilizados por diversos atores. Santos (2018) usa o termo "mobilização legal" para descrever a intensificação de mobilizações baseadas em direitos, salientando o processo de tradução de um dano percebido em uma afirmação de direitos. 
Assim, grupos subalternos reivindicam e negociam ativamente direitos, usando a lei como uma oportunidade de ação coletiva (Collins et al., 2010; Sousa-Santos; Rodríguez-Garavito, 2005). Se os direitos não são capazes, por si só, de transformar o contexto social que produz desigualdades e podem ser incorporados em complexas relações de poder, eles não devem ser automaticamente considerados como "paradoxos dolorosos" (Brown, 2000), ou pior, serem descartados. Os direitos fazem parte de um repertório que está sendo usado pelos movimentos sociais; podem trazer mudanças materiais concretas e produzir novos imaginários políticos. Portanto, nossa proposta aqui é analisar as formas com as quais as trabalhadoras domésticas se apropriaram dos seus direitos e as ações por elas desenvolvidas para torná-los efetivos em seu quotidiano.

Vianna (2013, p.28) demonstra o aspecto polissêmico dos direitos e destaca um desses aspectos como um amplo processo de "transformação, remodelação e conversão de histórias, vivências e relações em categorias, universos morais distintos, causas políticas". Nos termos da autora, aparatos institucionais em sua heterogeneidade, mobilizações políticas, estratégias de coletivização, dramas morais e angústias individuais também se cruzam ao significado dos "direitos", desvendando a dimensão socialmente fértil da elasticidade presente nesses significados. No caso específico das trabalhadoras sindicalizadas, ao acionarem a entidade, compreendem o sindicato como um espaço de luta por direitos e, em algumas situações, os motivos que as levam a procurar amparo legal são também perpassados por sentimentos de injustiça, abuso, desrespeito, dentre outros. Há uma demanda pelo respeito como pessoa, como indivíduo (Vidal, 2003). Os comportamentos "injustos" ou "humilhantes" por parte dos patrões possuem o aspecto de ofensas morais e denotam o desgaste da relação de trabalho, uma vez que já não se sentiam respeitadas em seu ofício, em suas tarefas e em sua dignidade.

A atuação das trabalhadoras domésticas em um movimento político nacional pela busca por direitos "vem de longe", tendo em vista que são mais de 80 anos em que essas mulheres, através da organização em associações e depois em sindicatos próprios da categoria (a partir da Constituição Federal de 1988 que lhes reconhece o direito a sindicalização), buscam por uma maior visibilidade. ${ }^{1}$ No período contemporâneo, registramos, em particular, a adoção da Convenção 189 pela OIT em junho de 2011, que garante o trabalho decente para as trabalhadoras domésticas, assim como seus desdobramentos no Brasil com a Emenda Constitucional de 2013, e posterior Lei complementar n.150 de 2015, que reconhece uma lista extensiva de direitos a essas trabalhadoras. ${ }^{2}$ Cabe, portanto, entender como, uma vez esses direitos conquistados, as trabalhadoras domésticas elaboram o entendimento sobre seus significados e procuram implementá-los tantos em suas relações cotidianas de trabalho, quanto em ações sindicais. 


\section{Negociando direitos no dia a dia}

A legislação de 2015, embora seja incompleta e mantenha ainda alguma diferenciação entre domésticas e demais categorias, atribui uma posição jurídica e política à essas trabalhadoras. É um reconhecimento, pelo menos simbólico, de que trabalho doméstico é um trabalho e merece direitos. No decorrer de nossas pesquisas, notamos que esse discurso de igualdade formal penetra o imaginário coletivo das trabalhadoras domésticas para além das dirigentes sindicalistas que lutaram por essa reforma legislativa.

Entrevistas com trabalhadoras domésticas não sindicalizadas revelaram um sentimento compartilhado de merecimento e de ter ganho algo que já estava muito atrasado. Os direitos funcionam nesse sentido para contrastar a figura da "velha", boa e servil doméstica, com a da "nova" moderna trabalhadora que tem direitos. Tanto que, no momento dos debates em torno da reforma constitucional de 2013, foi criado nas mídias um discurso de que "as empregadas de antigamente não existem mais" ou mesmo que teria sido apagada a figura da empregada, como colocado por exemplo pela matéria da revista Época. ${ }^{3}$ Consideramos que a "empregada de antigamente" seja a trabalhadora doméstica enquadrada em um modelo ideal de servidão desejado pelos patrões, uma vez que pode existir um horizonte moral da servidão, almejado pelos empregadores. É possível estar havendo um declínio da servidão, decorrente das mobilizações por parte das trabalhadoras domésticas amparadas pelos seus novos direitos. A "empregada de hoje" não se deixaria mais explorar tanto quanto a "empregada de antigamente". É a presença de dois movimentos: a mudança na legislação, com a garantia de direitos, mas também a existência da resistência, uma vez que as "empregadas" resistiam no passado e as trabalhadoras domésticas continuam resistindo nos dias de hoje (Pinto, 2019).

Quase todas as trabalhadoras participantes de nossas investigações já tinham ouvido falar da legislação de 2015 e entendiam que possuíam mais direitos, mesmo que muitas vezes não soubessem o conteúdo exato desses direitos. Quando questionadas sobre a lei, elas afirmam por exemplo: "demorou o suficiente", "nós merecemos esses direitos" ou "agora temos direitos". Uma entrevistada em São Paulo explicou que: "é uma profissão que existe há tanto tempo, mas nunca tivemos direitos. Pela primeira vez, a gente se sente quinem gente". Essa última afirmação liga, de maneira profunda, o fato de ter direitos ao sentimento de ser "gente", considerando que os direitos humanizam o trabalho doméstico lhe conferindo um valor social até então negado. Portanto, ter direitos produz um senso de autoestima e cidadania nas mulheres entrevistadas. Além do mais, os direitos simbolizam a forma máxima de reconhecimento pelo Estado e pela sociedade de que as trabalhadoras domésticas são trabalhadoras e cidadãs.

Embora as trabalhadoras domésticas já tivessem alguns direitos antes de 2015, o discurso das entrevistadas revela a magnitude do significado da legislação. As trabalhadoras domésticas fazem uso desse aparato legislativo como uma 
ferramenta, um instrumento para negociar melhores condições de trabalho e estabelecer um limite entre o que elas consideram justo ou injusto. As mulheres não sindicalizadas encontradas, em ambos os estudos, expressaram todo o tipo de reclamações contra seus empregadores: serem demitidas no "dia errado", ou seja, um dia que normalmente não seria dia de trabalho; serem insultadas ou desrespeitadas; não terem suas horas extras pagas; não receberem os benefícios sociais ou não terem concedido o período adequado de férias. Alguns desses itens estão de fato na lei, outros não (não há dia legalmente errado para demitir alguém), mas o que isso mostra é que as trabalhadoras domésticas se apropriaram do discurso de direitos para determinar o que podem aceitar no local de trabalho.

Destacamos aqui alguns exemplos de ação de resistência às relações de trabalho desiguais e opressoras, fundamentadas numa noção de direitos, merecimento e cidadania. O primeiro é o caso de Élida, moradora de Nova Iguaçu, na Baixada Fluminense, que fez um relato, aos risos, sobre o não cumprimento do horário de chegada ao trabalho, na casa da patroa. Geralmente, o horário combinado é em torno de 7 ou 8 horas da manhã, o que exige que as trabalhadoras domésticas remuneradas saiam de Nova Iguaçu ainda de madrugada. Élida contou que, mesmo a patroa pedindo para chegar às 8 horas, ela chegava às 11 horas. $\mathrm{E}$ ainda assim, se houvesse questionamento por parte da patroa, ela retrucava, justificando o atraso com o horário da saída que sempre ultrapassava as oito horas diárias de trabalho: "Ah, meu amor! Se ela reclamar, eu digo logo que eu nunca saio no horário certo da casa dela. Como é que eu vou chegar às 7, 8 horas, se eu nunca saio no meu horário, no horário da lei?! Eu hein!". Nessa narrativa fica explícito que a trabalhadora possui uma forma particular de interpretar a legislação ou o próprio direito acerca de sua carga horária de trabalho. Desse modo, ainda que não seja uma "perita" em trâmites legais/jurídicos, há uma noção mínima daquilo que está posto na "lei das domésticas" que, assim, respalda a trabalhadora de "burlar" e se esquivar de um tratamento por parte da patroa que não esteja em consonância com o que a vigente norma estabelece. São atos cotidianos e informais, como esse, que demonstram uma maneira peculiar de as trabalhadoras domésticas se auto defenderem, demandarem e colocar em prática aquilo que entendem como direitos.

Outro exemplo é a estratégia encontrada pelas trabalhadoras ao escolherem em quantas casas trabalhar por diária e selecionarem famílias com poucos membros. Isso representaria uma vontade de não se enquadrar em um sistema de domesticidade e exploração do trabalho, com famílias extensas, com altas demandas de organização, alimentação, limpeza, entre outros aspectos para serem executados por uma única trabalhadora doméstica. Embora, no pleito dos sindicatos, hajam questões específicas acerca da situação das diaristas e da sua falta de direitos (são consideradas autônomas, portanto, as disposições da Lei n.150 e seus atrelados benefícios sociais não se aplicam) podemos entender essas escolhas como uma forma de resistir e de garantir um trabalho digno e mais 
valorizado, onde essas trabalhadoras acionam brechas permitidas pela lei. Esse é o caso de Rosa, que não trabalha para famílias com mais de duas pessoas porque acredita que assim vai trabalhar menos e poderá assumir outras faxinas, podendo receber outras diárias em um único dia de trabalho, "lucrando mais".

Esses dois exemplos revelam a força dos arranjos informais no setor doméstico, assim como a complexidade das relações de poder e subalternidade entre patroa e empregada. Apesar das profundas assimetrias, existem (pequenas) margens de protesto por parte das trabalhadoras contra as regras por elas consideradas injustas e algumas tentativas claras de afirmar seu lugar de trabalhadora, negociar seus direitos e usar a lei como forma de obter condições mais favoráveis. Observamos, então, que a lei de 2015 permite um auto reconhecimento das domésticas como trabalhadoras, sustentando a percepção de cidadania e negociações individuais com seus empregadores. Mesmo quando não organizadas formalmente, as trabalhadoras domésticas utilizam táticas para enfrentar e contestar as relações de trabalho opressivas às quais são expostas. Elas buscam redefinir seus horários, diversificar os empregos para diminuir a relação de dependência e desafiam seus patrões se referindo diretamente a lei.

\section{Educação legal popular e judicialização da política}

Como discutido acima, as trabalhadoras domésticas não sindicalizadas sabem, em geral, que existe uma lei e que elas têm direitos, mas muitas vezes não conhecem o conteúdo exato desses direitos. Os sindicatos tornam-se, então, o órgão principal para informar as empregadas e, muitas vezes, os empregadores também; são obrigados a informar sua categoria profissional e intermediar nos conflitos entre patrões e empregadas, e, antes da reforma trabalhista de 2017, ainda tinham obrigação de homologar rescisão de contratos. Isso tem por implicação fundamental conceder aos sindicatos de trabalhadoras domésticas o poder de fornecer informações corretas sobre a lei e os direitos. Os sindicatos têm, portanto, o papel fundamental de sanar dúvidas e orientar as trabalhadoras para que não se submetam à condições precarizadas de trabalho (Guimarães, 2016). De fato, uma das principais atividades da entidade consiste em fazer "cálculos" para a trabalhadora demitida, para que ela saiba exatamente o lhe é devido. $\mathrm{Na}$ maioria dos casos, os cálculos dos próprios sindicatos são usados contra os dos contadores dos empregadores, revelando uma certa margem de poder de barganha na aplicação da lei a favor das domésticas.

Os sindicatos produzem também boletins informativos, com o apoio de seus aliados (CUT, Contracs, organizações feministas e redes internacionais), que distribuem em transportes públicos, na entrada de condomínios ou dos prédios onde as domésticas trabalham. Nesses boletins, são destacadas as principais disposições da Lei n.150/2015, relembrando, sempre, o papel dos sindicatos na luta pelos direitos e a importância das trabalhadoras em se sindicalizarem. A lei se tornou o ponto principal da agenda nas reuniões mensais dos sindicatos, e as líderes sempre aproveitam essas oportunidades para esclarecer dúvidas e lembrar 
à suas afiliadas os direitos que têm. Essa conscientização popular constitui um repertório de mobilização legal, comparável ao usado pelos movimentos feministas para disseminar o conhecimento jurídico em torno da violência de gênero (Santos, 2018). De fato, Themis, uma ONG feminista, apoiou ativamente a Fenatrad em seus esforços educacionais, desenvolvendo um aplicativo para celular chamado Laudelina - em referência à líder histórica Laudelina de Campos Mello - que fornece informações sobre a lei, encaminha as trabalhadoras para seus sindicatos e as ajuda a fazer seus "cálculos".

Identificamos também usos estratégicos da lei que podem ser caracterizados como uma forma de "judicialização por baixo" (Sieder et al., 2005). Apesar das limitações da lei, ela garante alguns direitos fundamentais, como carteira assinada e acesso à previdência social. Como a maioria dos empregadores tenta não respeitar essas disposições, se aproveitando das dificuldades da fiscalização em domicílios privados, as trabalhadoras domésticas encontraram suas próprias brechas legais e estão cada vez mais usando litígios individuais contra os empregadores. Ao ativar esses mecanismos judiciais, elas conseguem fazer cumprir a lei e fazer com que seus direitos sejam respeitados no nível individual. Um estudo da Lalabee ${ }^{4}$ e do Tribunal Regional do Trabalho (TRT) de São Paulo mostra que, em 2014, houve um aumento de $25 \%$ nas reclamações iniciadas por trabalhadoras domésticas contra seus empregadores, atingindo um total de 9.928 casos em 2014 comparado com $7.953 \mathrm{em} \mathrm{2013.} \mathrm{Entre} \mathrm{janeiro} \mathrm{e} \mathrm{junho} \mathrm{de} \mathrm{2015,}$ o TRT registrou 5.201 reclamações, em comparação com 4.587 em 2014 no mesmo período.

Os litígios são frequentemente o resultado de uma necessidade desesperada na ausência de mecanismos formalizados para resolver disputas laborais. Eunice, uma empregada doméstica não sindicalizada, fornece um exemplo disso. Ela veio ao sindicato porque seu empregador enviou uma carta alegando que ela havia parado de ir trabalhar, e que isso constituía motivo de demissão. Eunice afirma que um dia ela foi parada na entrada do prédio e foi impedida de acessar o apartamento que deveria limpar. Depois de alguns dias, ela recebeu uma carta de demissão. Com medo de perder o salário (já muito baixo), ela procurou o sindicato em busca de conselhos:

"A primeira vez que entrei em contato com o sindicato, eu nem sabia que havia um. Eu não sabia... Já passei por muitas situações, mas nunca fiz nada, nunca liguei para o sindicato antes. É a primeira vez que faço isso porque estava desesperada por causa dessa carta, não sabia mais o que fazer. Então saí procurando o sindicato, porque estava desesperada, não sabia se ia trabalhar ou não." (Eunice, entrevista em São Paulo, em 12 de agosto de 2015)

O caso de Eunice mostra que o sindicato é um instrumento para acessar o poder judicial. Em um setor de atividade tão informal e desigual, privado de controles e fiscalização governamentais, os litígios individuais aparecem como um mecanismo para garantir direitos e manter um padrão mínimo de vida em caso de demissão. 
Para muitas trabalhadoras domésticas, os litígios também são uma forma de reparação pela confiança quebrada com seu empregador (Vidal, 2003). Isso é ilustrado pelo caso de Cristina, líder do sindicato de Franca. Cristina começou a ter problemas com seu empregador depois de ter sofrido um acidente de trabalho. O empregador tentou a pressionar a pedir demissão, mas Cristina sabia que, se o fizesse, perderia todos os seus benefícios sociais; portanto, decidiu levar o caso ao tribunal do trabalho. Cristina afirma: "Entrei nesse processo não por causa do dinheiro, mas por causa da humilhação que sofri". Para ela, tornou-se insuportável ser tratada "como sujeira", depois de anos de bons e leais serviços ao empregador e justamente no momento em que ela estava tendo um problema de saúde. Mais do que as dificuldades financeiras, o que machucou Cristina é a falta de consideração da sua patroa. Para ela, o procedimento legal era a única maneira de combater essa injustiça: "a lei é a melhor proteção que as trabalhadoras domésticas têm, não podemos fazer justiça com nossas próprias mãos". Implícito aqui está o diferencial no poder de barganha entre trabalhadoras domésticas e seus empregadores, ao qual a lei fornece alguma forma de compensação.

Assim, podemos notar um crescente papel judicial dos sindicatos, aproximando nosso caso do que a literatura denominou de "judicialização por baixo". Por um lado, esse processo de judicialização pode ser analisado criticamente como uma individualização dos direitos coletivos (Biehl, 2013), que impõe uma carga burocrática excessiva aos sindicatos já precários. De fato, os sindicatos de trabalhadoras domésticas estão tendo que compensar a falta de fiscalização por parte do Estado e preencher as lacunas da legislação com suas ações judiciais. Isso contribui para despolitizar os debates sobre direitos, tornando-se uma questão de regulamentação legal e não mais de cidadania.

Por outro lado, esse processo também pode ser visto como um sinal de maior consciência jurídica e política por parte das trabalhadoras; as trabalhadoras domésticas sabem que têm direitos e encontram maneiras de reivindicá-los e torná-los efetivos. Os litígios são instrumentos imperfeitos, mas contribuem para tornar a lei mais eficaz e podem produzir mudanças materiais concretas na vida dessas mulheres. Quando ganham um processo, além da compensação financeiras, as trabalhadoras recebem também um reconhecimento público pelo seu trabalho e uma confirmação de que merecem ser tratadas de maneira digna. Portanto, a judicialização pode ser simultaneamente regulatória e emancipatória (Sieder, 2011), trazendo mais legitimidade e visibilidade às demandas das trabalhadoras domésticas.

\section{A luta sindical e o efeito "empoderador" dos direitos}

Por fim, destacamos que a lei de 2015 teve um efeito emancipatório para as líderes sindicalistas, fortalecendo um processo de ativação da cidadania. Notamos um grande investimento por parte dos sindicatos em capacitação, formação política e cidadã de seus membros. Trata-se nesse caso de formar uma 
"consciência de classe" e de valorizar politicamente o trabalho doméstico, demonstrando seu valor intrínseco para a sociedade. Os sindicatos produzem um discurso contra hegemônico sobre o trabalho doméstico como sendo a atividade que torna todas as outras atividades possíveis, o colocando assim não abaixo da pirâmide social, mas sim, no centro da sociedade e da economia. Como explica Lúcia Helena, presidenta do sindicato de Volta Redonda:

"O trabalho doméstico é o pior e o melhor de todos os trabalhos. Gera educação, saúde e bem-estar. Se o trabalho doméstico acabar, vai acabar todas as outras profissões. Todos precisam de uma trabalhadora doméstica; o médico, o professor, principalmente quando tem criança, eles precisam da trabalhadora doméstica para cuidar da casa, das crianças e da alimentação. Se o trabalho doméstico termina, o Brasil acaba. É um trabalho muito digno, que deveria ter muito valor, mas as pessoas não valorizam." (Lúcia Helena, entrevista em Volta Redonda, em 2 de agosto de 2017)

Ressaltamos nesse processo a parceria com a OIT que desenvolveu dois programas de formação junto com a Fenatrad desde os anos 2000: o Trabalho Doméstico Cidadão (TDC) em 2005 e os módulos "Fortalecendo os Sindicatos de Trabalhadoras Domésticas" em 2018. O TDC tinha o duplo objetivo de aumentar o nível de escolarização das trabalhadoras domésticas e promover a ampliação de seus direitos. De acordo com o Guia Para Programas de Qualificação Para as Trabalhadoras Domésticas da OIT (2011, p.9), o TDC foi um programa federal desenvolvido entre os anos de 2005 e 2007, no âmbito do Plano Setorial de Qualificação - Planseq - do Ministério do Trabalho e Emprego e em diálogo com as trabalhadoras domésticas remuneradas e suas organizações sindicais. As atividades do programa tiveram, ainda, o apoio das extintas Secretaria de Políticas de Promoção da Igualdade Racial (Seppir) e Secretaria de Políticas para as Mulheres (SPM), do Ministério da Educação (MEC), do Ministério das Cidades (Mcidades), do Ministério da Previdência Social (MPS), da Caixa Econômica Federal (CEF) e da Secretaria Geral da Presidência da República.

Havia uma previsão de que as ações do TDC levassem a uma "qualificação social e profissional" das trabalhadoras domésticas, proporcionando a elas um aumento de escolaridade, como mencionado anteriormente, mas também atividades que agregassem um entendimento em políticas públicas, que pudessem gerar a consolidação da representação das trabalhadoras domésticas e um consequente avanço de condições da categoria. O programa foi a primeira política pública a contar com a participação de trabalhadoras domésticas remuneradas, que eram planejadoras e também o público-alvo das ações. Estima-se que mais de 300 trabalhadoras domésticas foram beneficiadas no Brasil, com as atividades realizadas em seis estados: Bahia, Sergipe, Pernambuco, Maranhão, Rio de Janeiro e São Paulo. Possibilitou ainda a formação de novas líderes, como por exemplo a atual presidenta de Fenatrad, Luiza Batista, que foi recrutada através desse programa. 
Para as trabalhadoras domésticas, esses espaços educativos do TDC se tornaram ambientes de reconhecimento e de valorização do trabalho realizado por elas e de descobrimento do poder e da coragem dentro de cada uma. Para Alves (2013) esse espaço era um lugar de expressão pessoal e possibilidade de consolidação do processo emancipatório, de autonomia e organização como categoria profissional das trabalhadoras, mas também como uma direção para assimilação de conhecimentos, socialização de informações, aprendizagens e saberes. Essa parceria foi essencial também para garantir que a Fenatrad tenha um espaço nas negociações em torno da Convenção 189. No início de 2009, quando o Brasil teve envolvimento direto nos processos de informação e negociação, as dirigentes domésticas já estavam capacitadas e preparadas para levar suas demandas à OIT.

Com objetivos similares, a OIT e a Fenatrad lançaram em 2018 os módulos "Fortalecendo os Sindicatos de Trabalhadoras Domésticas". Com parcerias e orçamento mais restritos, esses módulos visam promover a formação das dirigentes para que possam fortalecer seus sindicatos, recrutar e formar novas lideranças em nível local. Os seis módulos são: formação política para as trabalhadoras domésticas; legislação nacional e normas internacionais; organização, função e história dos sindicatos; condições de trabalho; planejamento e comunicação. Esse material é concebido como uma forma de alcançar e formar as trabalhadoras domésticas, promovendo rodas de conversas facilitadas pelas próprias dirigentes sindicalistas. Os módulos são uma ferramenta para criar um espaço de diálogo e troca de experiência, permitindo que as trabalhadoras sejam mais cientes dos seus direitos e mais ativas nos seus sindicatos. Trata-se assim de um processo de auto formação e de fortalecimento dos sindicatos, visando explicitamente o conhecimento da Convenção 189 e da Lei n.150/2015.

Tal como foi com o TDC, esses módulos de formação permitem, além de uma capacitação formal em direitos e atuação sindical, um processo de empoderamento das trabalhadoras domésticas. Usando a perspectivas fornecida por Hill Collins (2000), conceituamos o "empoderamento" como um processo de transformação das relações sociais de dominação, expressas através do resgate da autoestima (sentimento individual de confiança), da capacidade de produzir novos conhecimentos sobre si próprio ou sobre o seu grupo (trabalhadoras domésticas como trabalhadoras), além de um maior grau de autonomia e capacidade de ação (defesa dos direitos da categoria). De fato, vemos acontecer nesses processos de formação uma afirmação do lugar da trabalhadora doméstica na sociedade, uma valorização de seu trabalho, e uma maior capacidade de enfrentar situações de exploração com as ferramentas da luta coletiva oferecidas pelos sindicatos.

Resgatando suas próprias histórias de luta, as trabalhadoras valorizam seus conhecimentos e relembram os sucessos da categoria. Destaca-se, ainda, a legitimidade para atuar como formadoras, fortalecendo sua autoestima e confiança nas suas próprias capacidades. Os referidos programas de formação tornam as 
trabalhadoras domésticas cidadãs ativas, sujeitos de direitos, em oposição à imagem tradicional da trabalhadora invisível e pouco qualificada, descendente de escravizada. A formação política e sindical permite redefinir o papel do trabalho doméstico na sociedade brasileira e empoderar as trabalhadoras a fim de lutar contra a exploração e opressão da categoria.

Nessa perspectiva de um efeito "empoderador" da luta pelos direitos, cabe destacar o Seminário "Trabalho Digno e Equidade de Direitos: Fortalecendo o Coletivo de Mulheres Trabalhadoras Domésticas para Fortalecer a Democracia", realizado no final do mês de março de 2018, na sede do Sindoméstico Nova Iguaçu, com financiamento de um edital do Fundo Elas (Building Movements - Feminismos Contemporâneos). Nessa ocasião, as duas pesquisadoras participaram como colaboradoras, ajudando na elaboração do projeto, ainda na fase da seleção do edital.

Com o valor recebido pelo edital, o Sindoméstico Nova Iguaçu planejou e executou um seminário para as 30 participantes vindas do estado do Rio de Janeiro e de outros sindicatos do Brasil. O mote principal do evento foi o intercâmbio com duas funcionárias terceirizadas do setor de limpeza da London School of Economics (local onde uma das pesquisadoras estava, na época, realizando sua tese): Mildred Simpson e Beverley Williams, do sindicato Vozes Unidas do Mundo (United Voices of the World), imigrantes jamaicanas, que compartilharam suas histórias de trabalho e de luta. O evento contou ainda com o apoio e presença de representantes do projeto UFF - Limpeza Total, ${ }^{5}$ da Rede Criola, CUT Mulheres, e da deputada federal Benedita da Silva. Ao longo de três dias, houve dinâmicas promovidas pela Rede Criola e atividades junto a CUT Mulheres - RJ, oficinas de oratória, apresentação do Aplicativo Laudelina por uma representante da ONG Themis, finalizando com uma atividade de planejamento das ações dos sindicatos, com o apoio da CUT.

A discussão do seminário foi pautada pela luta de coletivos de mulheres negras pela efetivação de seus direitos. O direito ao salário decente, a uma vida livre de violência, a ocupar os espaços públicos e políticos, foi colocado com força em um contexto de retrocessos organizados por um governo interino considerado como ilegítimo. Esse seminário mostra a importância dos direitos como vocabulário e como plataforma comum de ação, especialmente em um contexto de golpe e ataques neoliberais aos trabalhadores. Os direitos estão interligados às concepções de democracia e cidadania, como refletido no próprio título do evento, e nesse sentido, as tentativas do governo de diminuir a proteção dos trabalhadores são entendidas como um enfraquecimento da democracia. Direitos iguais são colocados como condição e expressão do Estado democrático. Portanto, a luta por direitos iguais e "trabalho decente" se torna uma luta por justiça social e democracia. As trabalhadoras domésticas situam sua luta num contexto mais amplo de luta contra o golpe, afirmando seu status de cidadãs e sua relevância no espaço dos movimentos sociais e do sindicalismo. 


\section{Considerações finais}

A partir das questões levantadas nesse texto, acreditamos que a prática cotidiana da resistência e a busca pela equidade de direitos sejam importantes estratégias por parte das trabalhadoras domésticas, sejam elas sindicalizadas ou não. Em se tratando das trabalhadoras não afiliadas aos sindicatos, é possível afirmar que possuem uma percepção crítica para a não efetivação dos direitos e, através de práticas de resistências cotidianas e informais vão se esquivando das opressões e demandando uma maior equidade de direitos no tratamento a elas dedicado pelas famílias empregadoras e no alcance de uma real cidadania. Embora não possuam o conhecimento técnico das leis, as trabalhadoras entrevistadas demonstram ter uma concepção própria do que são os seus direitos e afirmam, com força, ter o direito de ser tratadas com dignidade. Isso aparece na noção por elas expressa de "merecimento" e nas estratégias e tentativas de retomar um certo poder nas suas relações com os empregadores.

No caso das trabalhadoras sindicalizadas, por meio de instituições formais de luta por direitos, são acionadas legislações e demandas específicas para uma melhoria de sua ocupação e pela diminuição de opressões e desigualdades. Os sindicatos investiram no que se pode caracterizar como "educação legal popular", com o objetivo de informar e conscientizar a categoria sobre os seus direitos. Frente as deficiências da ação pública e falta de fiscalização por parte do Estado, as trabalhadoras domésticas se encontram responsáveis pela boa aplicação da lei e a efetivação de seus direitos. Por meio dos encontros e eventos realizados em dimensões nacionais, regionais e internacionais, essas mulheres vão se apropriando de um conhecimento que as empodera e torna conscientes de que são sujeitos de direitos e cidadãs acima de tudo, desenvolvendo práticas de resistências contra um severo quadro de disparidades e desigualdades. Essas mulheres trabalhadoras vão também elaborando uma nova forma de existência, forjando assim uma "re-existência" (Bernadino-Costa, 2007), reelaborando os significados de suas vivências e trajetórias enquanto pessoas, quando finalmente se sentem "que nem gente".

Sugerimos, portanto, que os direitos são um repertório de ação coletiva importante, embora tenham limites e ambivalências. Não tivemos o espaço para discutir em detalhes os problemas levantados pela Lei n.150 de 2015, escolhendo analisar aqui os usos que são feitos dessa legislação pelas próprias trabalhadoras. Esperamos contribuir com esse estudo aos ricos debates sobre direitos, mobilizações legais e resistências, demonstrando a relevância que o campo legal/ jurídico pode ter para os movimentos sociais e os grupos marginalizados. Os direitos se tornam um vocabulário, uma prática quotidiana e um instrumento possível de emancipação para as trabalhadoras domésticas com quem convivemos durante esses últimos anos. Esse exemplo nos instiga a pensar os direitos para além de quadros normativos ou de preocupações com "eficiência", como uma ferramenta necessária aos imaginários políticos e formas de se organizar dentro do Estado democrático. 
$1 \mathrm{O}$ início do movimento organizado é em geral datado à criação da primeira associação de trabalhadoras domésticas pela militante Laudelina de Campos Mello em 1936, na cidade de Santos. Para mais detalhes sobre a história do movimento e as conquistas legislativas ver por exemplo Bernardino-Costa (2015) e Kofes (2001).

2 Para uma análise da luta em torno da Convenção 189, suas origens e repercussões no Brasil, ver Acciari (2019).

3 Em janeiro de 2012, a matéria da Revista Época, com o título "Por que a empregada sumiu?", tornou pública a hipótese de que a trabalhadora doméstica remunerada desapareceria e que essa alteração seria difícil para muitas famílias brasileiras.

4 Lalabee Domésticas é um aplicativo destinado às trabalhadoras domésticas e aos seus empregadores, para que possam acessar, de forma rápida e objetiva, informações sobre o serviço e ter um controle maior sobre as horas gastas nos turnos de trabalho.

5 Projeto de educação popular para trabalhadores da limpeza terceirizados da Universidade Federal Fluminense - UFF.

\section{Referências}

ABU-LUGHOD, L. Do muslim women really need saving? Anthropological reflections on cultural relativism and its others. American Anthropologist, v.104, n.3, p.783-90, 2002 .

ACCIARI, L. Paradoxes of subaltern politics: Brazilian domestic workers' mobilisations to become workers and decolonise labour. London, 2018. Thesis (PhD) - The London School of Economics and Political Science. London, 2018.

Decolonising labour, reclaiming subaltern epistemologies: Brazilian domestic workers and the international struggle for labour rights. Contexto Internacional, v.41, n.1, p.39-63, 2019.

ALVES, F. E. De escrava a cidadã: educação, trabalho e emancipação das trabalhadoras domésticas. Salvador, 2013. Tese (Doutorado) - Programa de Pós-Graduação em Educação, Universidade Federal da Bahia. Salvador, 2013.

BERNARDINO-COSTA, J. Sindicatos das Trabalbadoras Domésticas no Brasil: teorias da descolonização e saberes subalternos. Brasília, 2007. Tese (Doutorado) - Programa de Pós-Graduação em Sociologia, Universidade de Brasília. Brasília, 2007.

Saberes subalternos e decolonialidade: os sindicatos das trabalhadoras domésticas no Brasil. Brasilia: UnB, 2015.

BIEHL, J. The judicialization of biopolitics: Claiming the right to pharmaceuticals in Brazilian courts. American Ethnologist, v.40, n.3, p.419-43, 2013.

BRADSHAW, S. Is the rights focus the right focus? Nicaraguan responses to the rights agenda. Third World Quarterly, v.27, n.7, p.1329-41, 2006.

BROWN, W. Suffering Rights as Paradoxes. Constellations, v.7, n.2, p.208-29, 2000.

COLLINS, D. et al. New Directions in Feminism and Human Rights. International Feminist Journal of Politics, v.12, n.3-4, p.298-318, 2010. 
CORNWALL, A.; MOLYNEUX, M. The Politics of Rights: Dilemmas for Feminist Praxis: An Introduction. Third World Quarterly, v.27, n.7, p.1175-91, 2006.

CORNWALL, A. et al. Development with a Body: Sexuality, Human Rights and Development. London: Zed Books, 2008.

CORRÊA, S. A categoria mulher não serve mais para a luta feminista. Sur - Revista Internacional de Direitos Humanos, v.13, n.24, p.215-25, 2016.

COUSO, J. et al. Cultures of Legality: Judicialization and Political Activism in Latin America. Cambridge: Cambridge University Press, 2013.

DANTAS, L. M. S. As domésticas vão acabar? Narrativas biográficas e o trabalho como duração e intersecção por meio de uma etnografia multi-situada - Belém/PA, Porto Alegre/RS e Salvador/BA. Porto Alegre, 2016. Tese (Doutorado em Antropologia Social) - Instituto de Filosofia e Ciências Humanas, Universidade Federal do Rio Grande do Sul. Porto Alegre, 2016.

DIEESE. O Emprego Doméstico no Brasil. Estudos e Pesquisas, n.68, p.1-27, 2013.

Trabalho Doméstico Remunerado - Síntese De Resultados Apurados Em 2016 - Sped (Abril/2017). Pesquisa de Emprego e Desemprego (PED), 2017, p.1-10.

DOMINGO, P. Ciudadanía, derechos y justicia en América Latina: Ciudadanización-judicialización de la política. Revista CIDOB, Los Retos de América Latina en un Mundo en Cambio, n.85/86, p.33-52, maio 2009.

ÉPOCA. Por que a empregada sumiu. São Paulo, Globo. 2012. Disponível em: <http://revistaepoca.globo.com/vida/noticia/2012/01/por-que-empregada-sumiu. html $\geq$. Acesso em: $28 \mathrm{dez} .2016$.

GIDEON, J. Accessing economic and social rights under neoliberalism: gender and rights in Chile. Third World Quarterly, v.27, n.7, p.1269-83, 2006.

GONZALEZ, L. Racismo e Sexismo na Cultura Brasileira. Revista Ciências Sociais Hoje - ANPOCS, p.223-44, 1984.

GREWAL, I. Women's Rights as Human Rights: The Transnational Production of the Global Feminist Subject. In: GREWAL, I. (Ed.) Transnational America: Feminisms, Diasporas, Neoliberalism. Durham: Duke University Press, 2005. p.121-57.

GUIMARÃES, N. A. Casa e mercado, amor e trabalho, natureza e profissão: controvérsias sobre o processo de mercantilização do trabalho de cuidado. Cadernos Pagu, n.46. Dossiê Gênero e Cuidado, p.59-77, jan.-abr. 2016.

HILL COLLINS, P. Black feminist thought: knowledge, consciousness, and the politics of empowerment. 2 ed. New York: Routledge, 2000.

KABEER, N. Globalization, labor standards, and women's rights: dilemmas of collective (in)action in an interdependent world. Feminist Economics, v.10, n.1, p.3-35, 2004.

KOFES, S. Mulher, mulheres: identidade, diferença e desigualdades na relação entre patroas e empregadas domésticas. Campinas: Editora da Unicamp, 2001.

MACKINNON, C. A. Rape, Genocide, and Women's Human Rights. Harvard Women's Law Journal, n.17, p.5-17, 1994.

MOHANTY, C. T. Under Western Eyes: Feminist Scholarship and Colonial Discourses. Feminist Review, n.30, p.61-88, 1988. 
OLIVEIRA, L. R. C. de. Direito legal e insulto moral: dilemas da cidadania no Brasil, Quebec e EUA. 2 ed. Rio de Janeiro: Garamond, 2011.

OIT. Guia para programas de qualificação para as trabalhadoras domésticas, Programa de Promoção da Igualdade de Gênero e Raça no Mundo do Trabalho. Brasília, 2011.

Convenção e recomendação sobre trabalho decente para as trabalhadoras e os trabalhadores domésticos. Novembro de 2011. Disponível em: <http://www.ilo.org/ wcmsp5/groups/public/ed_protect/protrav/_travail/documents/publication/ wcms_169517.pdf $\geq$. Acesso em: 21 mar. 2018.

PINTO, T. de O. "Eu tinha uma certa liberdade": famílias, direitos e dispositivos de resistência de trabalhadoras domésticas de Nova Iguaçu - RJ. Rio de Janeiro. Tese (Doutorado em História, Política e Bens Culturais) - Escola de Ciências Sociais, Fundação Getulio Vargas. Rio de Janeiro, 2019.

PITANGUY, J. Bridging the Local and the Global: Feminism in Brazil and the International Human Rights Agenda. Social Research, v.69, n.3, p.805-20, 2002.

SANTOS, C. M. Mobilizing Women's Human Rights: What/ Whose Knowledge Counts for Transnational Legal Mobilization? Journal of Human Rights Practice, v.10, p.191-211, 2018.

SARDENBERG, C. M. B. Liberal vs. Liberating Empowerment: A Latin American Feminist Perspective on Conceptualising Women's Empowerment. IDS Bulletin, v.39, n.6, p.18-27, 2008.

SIEDER, R. 'Emancipation' or 'regulation'? Law, globalization and indigenous peoples' rights in post-war Guatemala. Economy and Society, v.40, n.2, p.239-65, 2011.

SIEDER, R. et al. The Judicialization of Politics in Latin America. New York: Palgrave MacMillan, 2005.

SOUSA-SANTOS, B.; RODRÍGUEZ-GARAVITO, C. S. A. Law And Globalization From Below: Towards A Cosmopolitan Legality. Cambridge: Cambridge University Press, 2005.

SPIVAK, G. C. Outside in the teaching machine. New York: Routledge, 1993.

Righting wrongs. In: OWEN, N. (Ed.) Human Rights, Human Wrongs. Oxford: Oxford University Press, 2003. p.168-227.

VIANNA, A. O fazer e o desfazer dos direitos: experiências etnográficas sobre política, administração e moralidades. Rio de Janeiro: E-papers, 2013.

VIDAL, D. A linguagem do respeito. A experiência brasileira e o sentido da cidadania nas democracias modernas. Dados - Revista de Ciências Sociais, v.46, n.2, p.265-87, 2003 .

RESUMO - Formas de contestação das trabalhadoras domésticas contra a desvalorização do seu trabalho serão foco de análise do artigo, indo das negociações informais com os empregadores até a mobilização sindical. Demonstraremos que a luta principal dessas trabalhadoras gira em torno do reconhecimento e do valor do seu trabalho. Para tanto, as trabalhadoras propõem uma redefinição do conceito de trabalho, desafiando a dicotomia produtivo/improdutivo, buscando alcançar mais dignidade num setor marcado pela desigualdade e exploração. Ademais, os sindicatos desenvolvem estratégias cole- 
tivas pela efetivação da Lei n.150/2015, que garante direitos trabalhistas à categoria, se apoiando no discurso de "trabalho decente" da OIT e nas parcerias com outros movimentos sociais. Concluímos que a plena inclusão do trabalho de cuidado e reprodutivo na concepção de "trabalho" é indispensável para garantir dignidade e igualdade de direitos.

PALAVRAS ChaVES: Trabalho doméstico, Direitos, Mobilizações legais, Sindicatos.

ABSTRACT - This article focuses on the different ways domestic workers contest the devaluation of their work, ranging from informal negotiations with employers to union mobilization. We demonstrate that the main struggle of these workers revolves around the recognition and value of their work. To this end, domestic workers propose a redefinition of the concept of work that challenges the productive/unproductive dichotomy. They seek more dignity in a sector marked by inequality and exploitation. In addition, the unions have developed collective strategies for the implementation of Law n.150/2015, which guarantees labor rights for domestic workers, in keeping with the ILO's "decent work" discourse and their partnerships with other social movements. We conclude that the full inclusion of care and reproductive work in the concept of "work" is indispensable to ensure dignity and equal rights in this sector.

KErWORDS: Domestic work, Rights, Legal mobilizations, Labor unions.

Louisa Acciari é doutora em Estudos de Gênero pela London School of Economics and Political Science (LSE), mestre e graduada em Ciência Política pela Sciences Po Paris. Pós-doutoranda na Universidade Federal do Rio de Janeiro em Sociologia, e é pesquisadora associada do Departamento de Estudos de Gênero da LSE.

@ - louisa.acciaril@gmail.com / https://orcid.org/0000-0002-2335-7948

Tatiane de Oliveira Pinto é doutora em História, Política e Bens Culturais pelo Centro de Pesquisa e Documentação de História Contemporânea do Brasil da Fundação Getúlio Vargas (RJ), mestre em Economia Doméstica pela Universidade Federal de Viçosa, e graduada em Economia Doméstica pela Universidade Federal Rural do Rio de Janeiro. É professora na Universidade Federal Rural do Rio de Janeiro.

@ - oliveira.tatianede@gmail.com / https://orcid.org/0000-0002-9717-4597

Recebido em 10.12.2019 e aceito eem 14.2.2020.

I Instituto de Filosofia e Ciências Sociais, Universidade Federal do Rio de Janeiro, Rio de Jeneiro, Brasil.

II Departamento de Economia Doméstica e Hotelaria, Universidade Federal Rural do Rio de Janeiro, Rio de Janeiro, Brasil. 
